\title{
The Role of Maps in Neighborhood- Level Heat Vulnerability Assessment for the City of Toronto
}

\section{Claus Rinner}

Ryerson University

\section{Dianne Patychuk}

Steps to Equity

\section{Kate Bassil}

Toronto Public Health

\section{Shiraz Nasr}

Birzeit University

\section{Stephanie Gower}

Toronto Public Health

\section{digital.library.ryerson.ca/object/85}

\section{Please Cite:}

Rinner, C., Patychuk, D., Bassil, K., Nasr, S., Gower, S., \& Campbell, M. (2010). The role of maps in neighborhood-level heat vulnerability assessment for the city of Toronto. Cartography and Geographic Information Science, 37(1), 31-44. doi:10.1559/152304010790588089

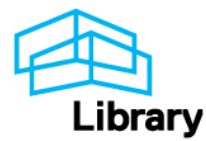




\title{
The Role of Maps in Neighborhood-level Heat Vulnerability Assessment for the City of Toronto
}

\section{Claus Rinner, Dianne Patychuk, Kate Bassil, Shiraz Nasr, Stephanie Gower, and Monica Campbell}

\begin{abstract}
Extreme hot weather is a threat to public health, and it is anticipated that the number of hot days and the duration of extreme heat events will increase with climate change. Already, heatrelated illness and mortality is the dominant natural hazard in many countries. While everybody is at risk to varying degrees, there are known factors relating to heat exposure and sensitivity that make some population groups more vulnerable than others. The objective of this paper is to assess cartographic design decisions in creating heat vulnerability maps, and how they may affect the usefulness of different map types. Spatial patterns of heat vulnerability were visualized using maps representing individual exposure and sensitivity indicators, composite vulnerability indices, and geographical hot spots of vulnerability. The composite indices were calculated using the ordered weighted averaging (OWA) multi-criteria analysis method. Hot spots were determined using local indicators of spatial association (LISA). This study is part of an ongoing project which aims to identify vulnerable populations within the City of Toronto, Canada, in order to support targeted response and mitigation. The maps were found to be a valuable addition to the hot weather planning toolkit supporting neighborhood-level interventions.
\end{abstract}

KEYWORDS: Climate change, cluster maps, geographic information systems, heat-related illness, multi-criteria analysis, vulnerability index

\section{Introduction}

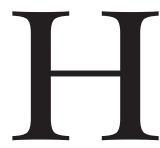
ot weather can have a serious impact on human health. Researchers have studied the effects of extreme heat events on the human body and found a spectrum of impacts ranging from heat rash and sun burn to more complicated illnesses such as heat cramps, fainting, and heat exhaustion (SmoyerTomic and Rainham 2001; Basu and Samet 2002; Smoyer-Tomic et al. 2003; Ebi 2007; Pengelly et al. 2007). Heat stroke is the most severe illness related to heat and occurs when the body's core temperature reaches $41^{\circ} \mathrm{C}$ or more (Ebi 2007). This usually only occurs when heat exhaustion is not noticed or treated, and it is accompanied by hot, dry skin, fast pulse, headache, or coma. Heat stroke can result in complications including kidney, liver, and brain damage and ultimately death (Barrow and Clark 1998; Bouchama and Knochel 2002). According to statistics available from the U.S. National Weather Service, over the past ten years, heat accounted for almost half of all deaths and injuries attributed to atmospheric phenomena in the country-more than any other weather-related cause (NWS 2008).

The health effects vary depending upon the length and severity of the heat wave as well as the body's ability to dissipate extra heat. A number of studies have shown that heat-related mortality significantly increases during prolonged hot and oppressive weather conditions (Kalkstein and Greene 1997; Kilbourne 1997); this impact is exacerbated with the additional effect of air pollution (Cheng et al. 2007). Further, morbidity as indicated by emergency calls and emergency department visits has also been shown to increase during periods of high daily temperatures (Semenza et al. 1999; Dolney and Sheridan 2006; Bassil et al. 2007).

\footnotetext{
Claus Rinner, Department of Geography, Ryerson University, 350 Victoria Street, Toronto, Ontario, M5B 2K3 Canada. Ph: 4169795000 x 2686; Email: <crinner@ryerson.ca>. Dianne Patychuk, Steps to Equity, 166 Curzon Street, Toronto,, Ontario M4M 3B5 Canada. Ph: 416462 9249; Email: <dpatychuk@sympatico.ca>. Kate Bassil, Simon Fraser University, Faculty of Health Sciences, 8888 University Drive, Burnaby, BC V5A 1 S6 Canada. Ph: 778782 8644; Email: <kate_bassil@sfu.ca>. Shiraz Nasr, Department of Geography, Ryerson University, 350 Victoria Street, Toronto, Ontario, M5B 2K3 Canada. Email: <snasr@ryerson.ca>. Stephanie Gower, Toronto Public Health, 277 Victoria Street, 7th Floor, Toronto, Ontario, M5B 1W2 Canada. Ph: 416338 8101; Email: <sgower@toronto.ca>. Monica Campbell, Toronto Public Health, 277 Victoria Street, 7th Floor, Toronto, Ontario, M5B 1W2 Canada. Ph: 416338 8091; Email: <mcampbe2@toronto.ca>.
} 
Populations in temperate regions tend to be at an increased risk for heat stress in comparison with warmer regions, in large part due to the greater seasonal fluctuation in temperatures and the lack of acclimatization to increasing temperatures (Kalkstein and Davis 1989; Basu and Samet 2002). The health impacts of insufficient acclimatization have been demonstrated in studies which suggest that heat waves earlier in the season result in more deaths than those occurring later in the summer (Kalkstein and Davis 1989).

Environment Canada predicts that the number of days with temperatures over 30 degrees in Toronto will more than triple from about 15 days per year between 1961-1990 to about 65 days per year by 2080-2100. A historical analysis of heat-related mortality for the period 1953 to 2000 estimated that on average, 120 people die prematurely each year in Toronto due to summer heat, with large variations from year to year depending on weather conditions (Pengelly et al. 2007). Many studies indicate that urban areas such as Toronto are at increased risk for health effects from increased heat. The urban environment poses a particular risk for heat episodes, given the presence of the "urban heat island" where temperatures can range up to $11^{\circ} \mathrm{C}$ warmer than surrounding regions due to limited vegetative cover and large expanses of asphalt (Aniello et al. 1995).

The City of Toronto has a heat health alert system in place which guides the Medical Officer of Health in calling heat alerts when the weather conditions pose an increased risk to health (Toronto Public Health 2009a). In response to an alert, Toronto's hot weather response plan is activated by Toronto Public Health, which initiates a number of interventions including mass media broadcast messaging, opening cooling centers, and providing outreach through social services. Over the summer of 2007 there were 10 days with a heat alert and five days with an extreme heat alert (Toronto Public Health 2009a). Over the summer of 2008, there were three days with a heat alert and six days with an extreme heat alert (Toronto Public Health 2009a).

In addition to the general physiological risk of heatrelated illness there are intrinsic and extrinsic factors that can increase this risk for individual persons and for population groups, making them particularly vulnerable. Brooks (2003) makes a distinction between biophysical and social vulnerability. Similarly, Füssel et al. (2004) propose a series of conceptual frameworks for adaptation to the health effects of climate change, in which they emphasize the role of non-climatic risk factors, including demographic characteristics, housing conditions, and individual behaviors. Yohe and Ebi (2005) compare the concept of vulnerability in the climate change and public health communities. They note that "within the health sector, vulnerability is viewed as the current or baseline state, not as the residual state after adaptive capacity has been considered" (Yohe and Ebi 2005, p. 21). Thus, public health planning is based on current vulnerability, the status prior to any intervention.

"Reaching those who are most vulnerable and at-risk" is identified as a continuing challenge by the Medical Officer of Health in a review of heat response activities during the summer of 2007 (Toronto Public Health 2007, p. 1). A report by Mersereau (2007) also notes the challenge of "identifying and targeting vulnerable populations" and observes that "municipal decisionmakers in the [Greater Toronto Area] do not have the data, tools, and/or expertise to incorporate information about housing-stock or population demographics into their decision-making processes" (p. 30).

The purpose of this research is to develop mapping tools to identify vulnerable populations and places in order to guide short-term public health interventions as well as longer-term urban planning. This paper illustrates preliminary results and discusses critical decisions in the mapping process, such as geographic scale and aggregation, variable selection, and the parameters for composite indexing and cluster analysis. It is anticipated that spatially explicit, intraurban, neighborhood-level adaptation will contribute to reducing heat-related illness and mortality, and mitigate the urban heat island effect. Access to a mapping tool will enable health department staff and their community partners to make better use of limited outreach resources through targeting interventions, thereby improving the overall cost-effectiveness of heat response programs.

The remainder of this paper is structured as follows. The next section summarizes previous research on human heat vulnerability, current approaches to neighborhood-level assessment of heat vulnerability, and geovisualization and map use in climate change research. The following section describes the data and methods used in this project. This is followed by a presentation and discussion of preliminary results with a focus on the exploratory mapping approach and the factors influencing the usefulness of maps. The paper concludes with a summary and outlook on future research.

\section{Research Background}

\section{Population Vulnerability to Extreme Heat}

The factors that increase the risk of heat-related illness in individuals and population groups are 


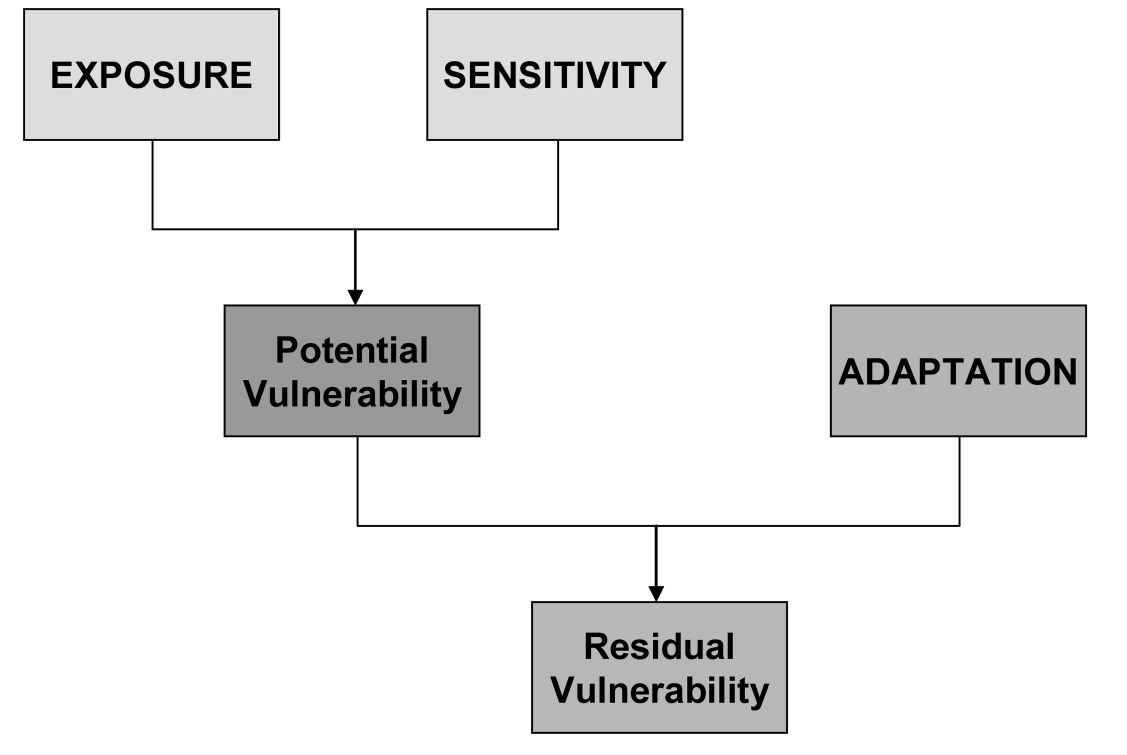

Figure 1. Conceptual framework for heat vulnerability (adapted from Schroeter et al. 2004, and Ebi et al. 2005)

often structured according to the three general aspects of climate change vulnerability: exposure, sensitivity, and adaptive capacity (Walker 2006; Séguin and Clarke 2008). They can be grouped into socio-demographic and healthrelated physiological risk factors, behavioral risk factors, and risk factors relating to the physical, built, and social environment. Individual risk factors and indicators for measuring the risk have been proposed in a number of studies, including Greenburg et al. (1983); Cutter et al. (2000); McGeehin and Mirabelli (2001); SmoyerTomic and Rainham (2001); Smoyer-Tomic et al. (2003); Harlan et al.(2006); and Tan (2008). For example, the City of Toronto's Hot Weather Response Plan (Toronto Public Health 2009b, p. 2) lists socially isolated seniors as the highest-risk group, followed by people with chronic diseases including mental illness, children, and the marginally housed or homeless.

To characterize heat vulnerability for the purpose of this study, we used a simple conceptual framework, adapted from the work by Schroeter et al. (2004) and Ebi et al. (2005). In the framework shown in Figure 1, the first component of heat vulnerability is the exposure to heat as an external, physical impact on individuals. The degree to which this impact affects a person is determined by their sensitivity, a component that is internal to the host and his/her life circumstances and social networks. As shown in Figure 1, exposure and sensitivity combine to form potential vulnerability which represents the pos- sible impact (or baseline vulnerability) prior to any response and mitigation activities. However, many jurisdictions conduct hot weather interventions. These short-term interventions (response) as well as long-term interventions (mitigation) are included in the framework as adaptation which reduces potential vulnerability to residual, post-adaptation vulnerability.

Analysts increasingly combine multiple indicators into composite measures (indices) of health, health inequalities, or health-related deprivation. Cutter et al. (2003) construct a social vulnerability index using countylevel socioeconomic and demographic data in the United States. Vincent (2004) proposes an index of social vulnerability to climate change for Africa, based on a weighted average of five sub-indices representing economic, demographic, infrastructure, global inter-connectivity, and resource dependence factors at a country level. Schuurman et al. (2007) provide an overview of commonly used, area-based deprivation indices. They also present a tabular overview of the type of index, categories of variables used, variable weighting method, and geographic unit of analysis (Schuurman et al. 2007, p. 594). Approaches to achieve a weighting of the importance of different deprivation indicators include principal components analysis, variable transformation/standardization, and expert weighting.

Rinner and Taranu (2006) propose to assess population health using GIS-based multi-criteria evaluation (MCE). Generally, MCE supports decision-makers with a recommendation of a course of action to be taken. The recommendation is based on the integration of multiple decision criteria into a single evaluation score for each decision alternative. Rinner and Taranu (2006) employ the analytic hierarchy process (AHP) to structure and weight non-medical determinants of health for public health units across Ontario. Bell et al. (2007) also use a GIS-based multi-criteria method to construct a health-related index. They build a socio-economic deprivation index from census data using ordered weighted averaging (OWA). 
The OWA method allows the decision-maker to specify a decision strategy in terms of the degree of "risk" to be taken, and the allowable trade-off between criteria (Malczewski and Rinner 2005).

\section{Spatially Explicit Heat Vulnerability}

\section{Assessment}

Existing municipal hot weather response plans frequently refer to vulnerable populations when describing targeted prevention or response action to address a heat alert. Many heat response measures such as notifications, distribution of water, or evacuation to cool places are directed at known, registered high-risk individuals at their residential locations, as well as facilities with known or suspected concentrations of high-risk individuals (a distinction made by U.S. EPA 2006, p. 22). However, between the level of individual person or facility, and the broad scope of addressing the general public, there are few interventions directed at the intermediate levels of target population groups or places. Currently, no outreach activities are conducted at a neighborhood level in Toronto with the exception of the cool places operated by the City and the activation of community agencies, which may intervene in specific neighborhoods.

In a research project entitled "Spatial vulnerability analysis of urban populations to extreme heat events" at Monash University's Climate Group (Melbourne, Australia) in collaboration with the Department of Human Services, State of Victoria, Australia, researchers are creating a vulnerability index in order to visualize spatial patterns of vulnerability across the City of Melbourne (Loughnan 2009). The project goals are to "target behavioral adaptation" and to "implement heat wave response plans within the communities with the highest risk" (Loughnan 2009, p. 1) as well as to support longerterm planning to mitigate the urban heat island effect. Other related work includes a study by the U.S. National Center for Atmospheric Research in collaboration with the U.S. Environmental Protection Agency and Arizona State University, entitled "Exploring spatial patterns of societal vulnerability to extreme heat." The project team conducts spatial analysis of heat vulnerability in Philadelphia and Phoenix (Wilhelmi 2007). The same researchers state that the "combination of social and physical factors allowed for identification of areas and population at risk from excessive heat" (Wilhelmi et al. 2008, p. 1). For the City of London, U.K., McGregor and Wolf (2008) present an approach where they classify nine vulnerabil- ity indicators into deciles and then combine the decile scores into a vulnerability index in order to map hot spots. Another study was designed at Indiana University to predict heat-related mortality in Philadelphia from heat exposure and risk factors using geo-statistical methods (Johnson and Wilson 2009). However, to our knowledge, a spatially explicit heat vulnerability assessment is not yet operational anywhere.

Although intra-urban heat vulnerability assessment can be assumed to be more accurate than a-spatial assessments at the city or country level, it is still conducted at aggregated geographic levels (e.g., neighborhoods) and, therefore, susceptible to the modifiable areal unit problem (MAUP) (Openshaw 1984). The MAUP describes the dependency of spatial relationships within and between variables, on the zoning and scale of geographic reference units. The zoning in many geographic datasets, such as census data, is independent of the phenomenon under investigation and must therefore be considered arbitrary. Furthermore, the MAUP affects the transition from one geographic scale to another. For example, Swift et al. (2008) found that point data for disease events aggregated to larger polygons had a correlation of 0.81 , while the correlation for the same data aggregated to smaller polygons was only 0.47 . Incidence rates for larger spatial units tend to be based on larger samples and be more stable because local variations are smoothed out. However, public health decision-making may require more detailed data distinguishing between higher and lower incidence rates (Swift et al. 2008). The MAUP requires decisions on the geographic level of analysis, depending on the characteristics of the individual study and available datasets.

\section{Geovisualization and the Role of Maps in Climate Change Research}

Mapping is an important tool for exploring data and communicating results in order to derive measures for policy intervention in climate change (Adger 2006; Eakin and Luers 2006). Maps are considered most powerful for detecting general spatial patterns and trends, while data tables and lists are the more useful tools to retrieve specific information from a dataset (Slocum et al. 2009). Geographic information systems (GIS) have been extensively used for mapping vulnerability to different environmental hazards (Cutter et al. 2003).

Cartographers have developed extensive guidelines for creating effective thematic maps. For 


\begin{tabular}{|c|c|c|}
\hline Exposure & Sensitivity & Adaptation \\
\hline & Pre-existing/chronic illness & \\
& Cognitive impairment & \\
Eutdoor surface/air temperature & Infants and young children & Home cooling, common cool rooms \\
Lack of tree canopy, green spaces & Low-income households & Hostels, drop-in centers \\
Old dwellings without A/C & Rental households & Participating community outreach centers \\
High-density dwellings without A/C & Cocially isolated people & Cooling centers, libraries, malls \\
Behavior (recreation and events) & Homeless & \\
& Low education level & \\
& Not English speaking & \\
& Recent immigrants & \\
& Racialized groups & \\
\hline
\end{tabular}

Table 1. Risk factors for a Toronto-specific heat vulnerability assessment.

example, McKendry and Machlis (2008) discuss a map of global climate change effects published in a report by the Intergovernmental Panel on Climate Change. Their critique includes the recommendations to use an equal-area projection, provide more focus to the map and simplify the legend, use the lightness instead of the hue aspect of color in order to represent temperature as a continuous, quantitative phenomenon, and to improve the visual hierarchy and consistency between map title and legend, and the actual contents of the map itself. These recommendations are based on standard resources for cartographic design such as Slocum et al. (2009).

The nature of maps is changing dramatically with the advent of more powerful computer hardware and easier-to-use mapping software. An important direction of cartographic research and practice is the promotion of highly interactive maps used for data exploration and hypothesis generation early in an analytical process. This concept of geographic visualization has been introduced by Monmonier (1989), DiBiase (1990), and MacEachren (1994). Examples of applications to public health are presented by MacEachren et al. (1998), Jankowski et al. (2001), and Rinner and Taranu (2006). Increasingly, maps are considered as a tool for visual spatial data analysis and combined with analytical tools (Rinner 2007).

\section{Data and Methods}

This study was conducted at different geographic scales within the City of Toronto, which is located in the Greater Toronto Area, on the north shore of Lake Ontario in southern Ontario, Canada. The scales employed within the City boundaries included the dissemination area (DA) and census tract (CT) levels of Canadian census geography as well as the City neighborhood. The DAs have a target population size of 400-700 persons, while CTs "usually have a population of 2,500 to 8,000" (Statistics Canada 2009). There are approximately 525 CTs, which have been combined by Toronto's Social Policy \& Research Unit into 140 neighborhoods (City of Toronto 2009a).

In an ongoing project to explore the spatial patterns of heat vulnerability within the City, indicator maps were created to represent risk factors for exposure and sensitivity. Next, index maps were developed in which multiple indicators were weighted and combined into a composite measure of heat vulnerability. Finally, cluster maps were produced to highlight areal concentrations of vulnerable populations. The static maps were created using ArcGIS for visual analysis on screen and in print. Interactive maps of vulnerability indices and clusters were explored using CommonGIS and GeoDA, respectively.

Based on the review of the literature on heat vulnerability and taking into account the local conditions, the risk factors shown in Table 1 were considered to be essential in order to assess heat vulnerability for Toronto. A satellite thermal image received from Natural Resources Canada was used to represent actual heat exposure. The image represents estimated outdoor surface temperatures on September 3, 2008, at approximately 10 a.m. (Maloley 2009). The zonal statistics function in ArcGIS was used to extract the mean temperature for each CT and save it with the CT boundary data set. Indicators for sensitivity to heat-related illness were selected from the 2001 and 2006 Canadian Census and the 2006 census target profile for seniors 
made available through the Community Social Data Strategy (City of Toronto 2009b). Selected facilities that represent adaptation measures in Table 1 will be mapped in the future to offset exposure and sensitivity according to the project's conceptual framework (Figure 1).

A Toronto-specific challenge results from the fact that about half of the City's residents are immigrants and close to half of the population have a mother tongue other than Canada's two official languages. At-risk groups therefore include residents who have difficulty understanding English information and recent immigrants unaware of how to access services. These access barriers are aggravated by other risk factors such as high heat exposure and low income.

This study uses multi-criteria analysis similarly to the exploration of residential quality of life by Malczewski and Rinner (2005) and the construction of a socio-economic deprivation index by Bell et al. (2007). Both of these author groups also demonstrate the use of ordered weighted averaging (OWA) (Yager 1988), a family of multi-criteria operators allowing the decision-maker to apply weights of importance to the criteria, as well as specify an attitude towards decision risk. A decision strategy can be specified mathematically (using an additional set of weights) on a scale from riskaverse ("pessimistic") to risk-taking ("optimistic") (Rinner and Malczewski 2002).

Local indicators of spatial association (LISA) (Anselin 1995) identify clusters of high, low, or opposite values within one variable or between two variables. For example, a statistically significant accumulation of areas with high values will be highlighted as the core of a high-value cluster. Cutter and Finch (2008) use this approach to further test the social vulnerability index developed by Cutter et al. (2003) for U.S. counties. Bassil (2008) applies the LISA method to the proportion of heat-related 911 calls by Toronto neighborhoods to identify local clusters of high burden of heat-related illness.

In transitioning from conceptual risk factors (Table 1) to measurable indicators, the availability of specific data limited the accuracy of the heat vulnerability assessment. For example, socio-economic data rely on the residence of census population. Like other urban centres, Toronto has an important population of marginally housed and homeless who are often not captured in government statistics. Another example relates to using building age as a proxy for heat exposure through lack of air conditioning. In fact, many older buildings in Toronto are located in treed neighborhoods and have been renovated to the highest standards of insulation and/or air conditioning.

\section{Results and Discussion}

Toronto Public Health staff found the indicator and index maps highly useful to assess intraurban patterns of heat vulnerability. While introducing a certain level of inaccuracy through data aggregation to administrative boundaries, this approach was deemed in line with the general perspective of public health institutions developing policies and interventions at the population rather than the individual level. The following text discusses specific parameters in visualization and analysis which influence the accuracy and usefulness of heat vulnerability maps.

\section{Geographic Aggregation and Scale Effects}

As a continuous phenomenon, surface temperature is best represented through a raster map (Figure 2a. However, in order to achieve visual and analytical comparability with populationbased indicators, the temperature data from the thermal image was also aggregated to administrative boundaries (census tracts) and displayed as a choropleth map (Figure 2b). Despite the known issues of the choropleth map which represents potentially non homogeneous areas with a single symbol (color), we determined visually that the overall spatial pattern of heat exposure was well preserved in the aggregated data. We therefore proceeded to combine them with areabased sensitivity indicators in a composite index of heat vulnerability.

In order to assess the impact of geographic scale on the usefulness of the indicator maps, experimentation with different scales took place. Figure 3 shows the concentration of high-rise buildings (measured as the proportion of dwelling units located in buildings with five or more storeys). This is a highly inhomogeneous indicator of potential exposure to heat, which is best mapped at the largest (most detailed) geographic scale of the census dissemination area (Figure 3a). The census tract (Figure 3b) and City neighborhood levels (Figure 3c) preserve the concentration of high-rise buildings located in the downtown core and along the central shore of Lake Ontario, but blur the characteristic spatial pattern of high-rises along major highways elsewhere in the City. Using the smaller scale (less detailed) maps would negatively 


\section{Outdoor Heat Exposure}

\section{Surface temperature, Toronto, Sept. 2008}

(a)

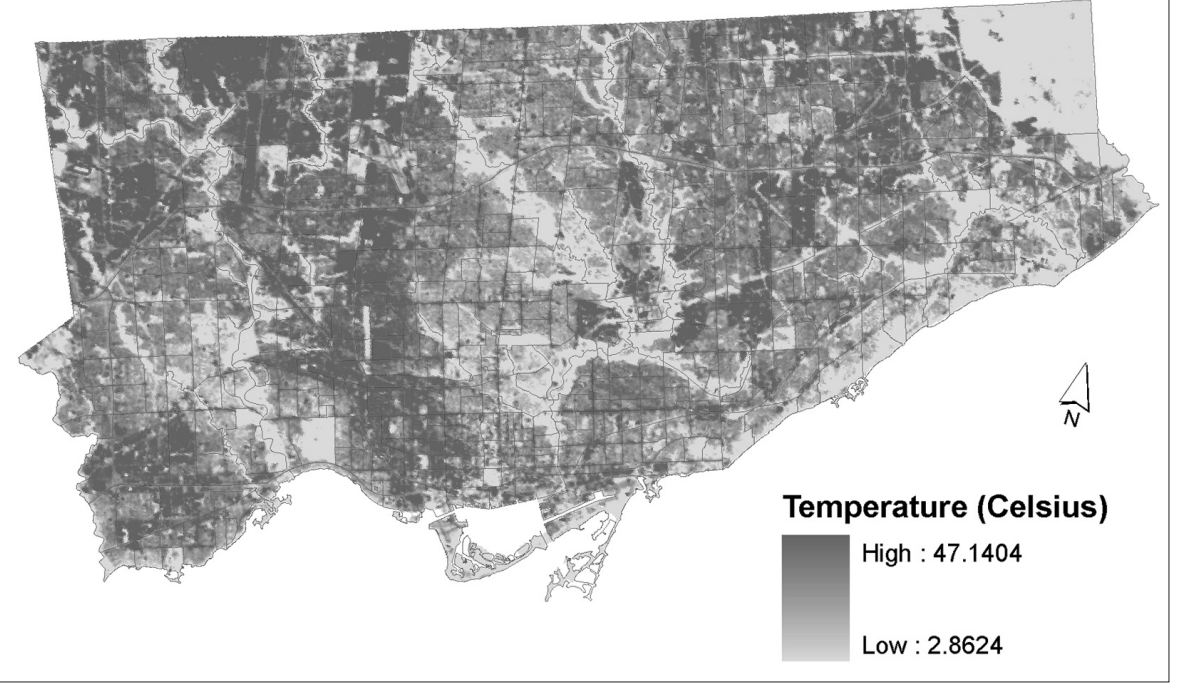

\section{Outdoor Heat Exposure Mean temperature, Toronto, Sept. 2008}

(b)

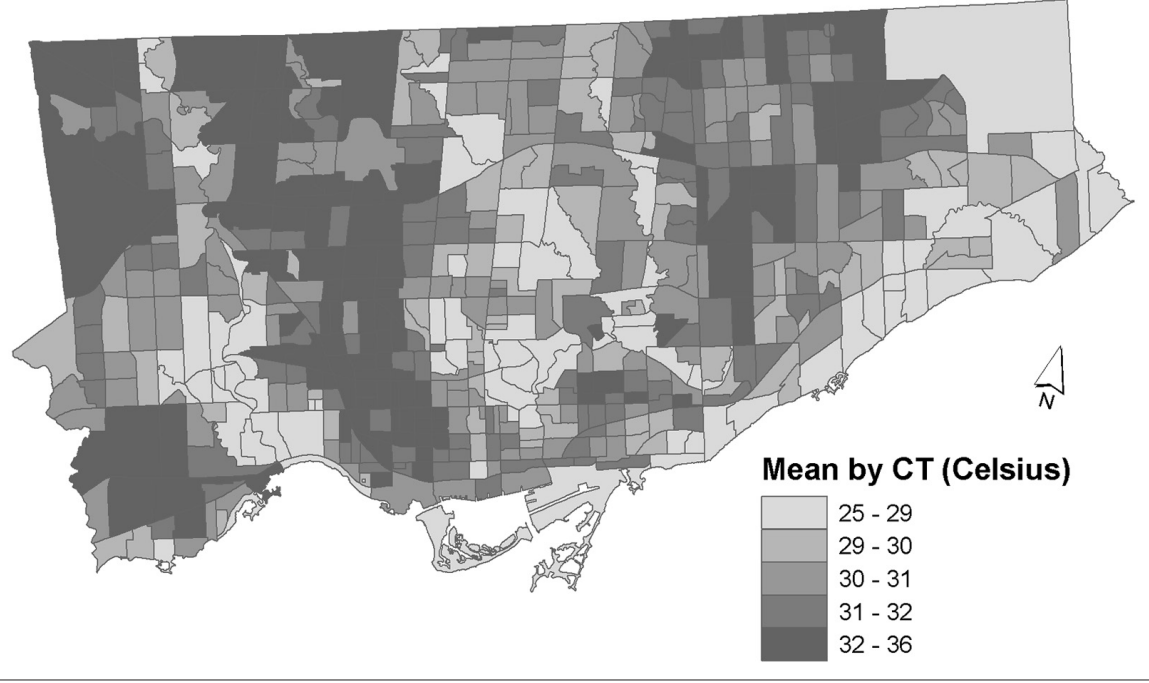

Figure 2. Effects of data representation. (a) Thermal remote sensing image vs. (b) aggregation of mean temperature by census tract. (Data sources: Natural Resources Canada, Statistics Canada.)

affect the ability to target areas of high potential exposure with specific outreach measures.

\section{Impact of Variable Selections}

Other studies which assess population sensitivity to heat-related illness use individual census variables as indicators and occasionally combine these into composite indices of vulnerability (e.g., Vincent 2004). In exploring the mechanisms of sensitivity to heat, we realized that it would often be useful to narrow the sensitive population by capturing combinations of risk factors. For example, instead of simply overlaying the sensitivity indicators of lowincome and elderly (aged 65 and over) populations (Figure $4 a)$, we propose to use selected cross-tabulations such as the proportion of low-income persons among the elderly (Figure 4b). The spatial distribution of the variables differs significantly. For example, there are a number of CTs along highway 401 in the western central part of the City which are characterized by high levels of the composite index of low-income and elderly. However, many of these CTs do not have a significant proportion of low-income persons among the elderly. Conversely, a number of CTs along the Gardiner Expressway in the downtown area show high proportions of low-income elderly, although the overlay of the related individual variables does not indicate sensitivity.

An additional challenge occurred with the commonly used risk factor of being elderly and living alone. In Toronto, we found that certain areas in the central part of the City with high proportions of elderly living alone were among the wealthiest neighborhoods. It is anecdotally known that elderly living alone in these old-grown, shaded neighborhoods tend to be well equipped with air conditioning and other resources to stay 
cool during a heat event. This observation indicates the need to add an additional controlling factor, such as low-income, to an already cross-tabulated indicator (i.e., elderly living alone).

\section{Consideration of}

\section{Decision-Makers' Needs}

This project uses a task-oriented approach to creating "information products" (Tomlinson 2007) which address specific decisionmaking needs by the endusers, in this case City staff who plan and conduct hot weather response activities. In particular, we argue that there cannot be a single solution to identifying vulnerable populations and hot spots of vulnerability. Instead, the vulnerability assessment must be adapted to specific interventions. For example, the distribution of general information on how to cope with extreme heat could be prioritized by a vulnerability index for the general population (Figure 5a). However, the planning of resources for evacuation of vulnerable residents to cooling centers should be based on a more specific measure, such as a vulnerability index focusing on elderly populations (Figure 5b).

The general population index was composed of the following standardized variables and weights: dwellings requiring major repairs (5 percent), dwellings constructed before 1986 (5 percent), apartments in buildings with five or more storeys ( 5 percent), dwellings rented ( 5 percent), low income persons before tax (15 percent), speaking neither English nor French (10 percent), recent

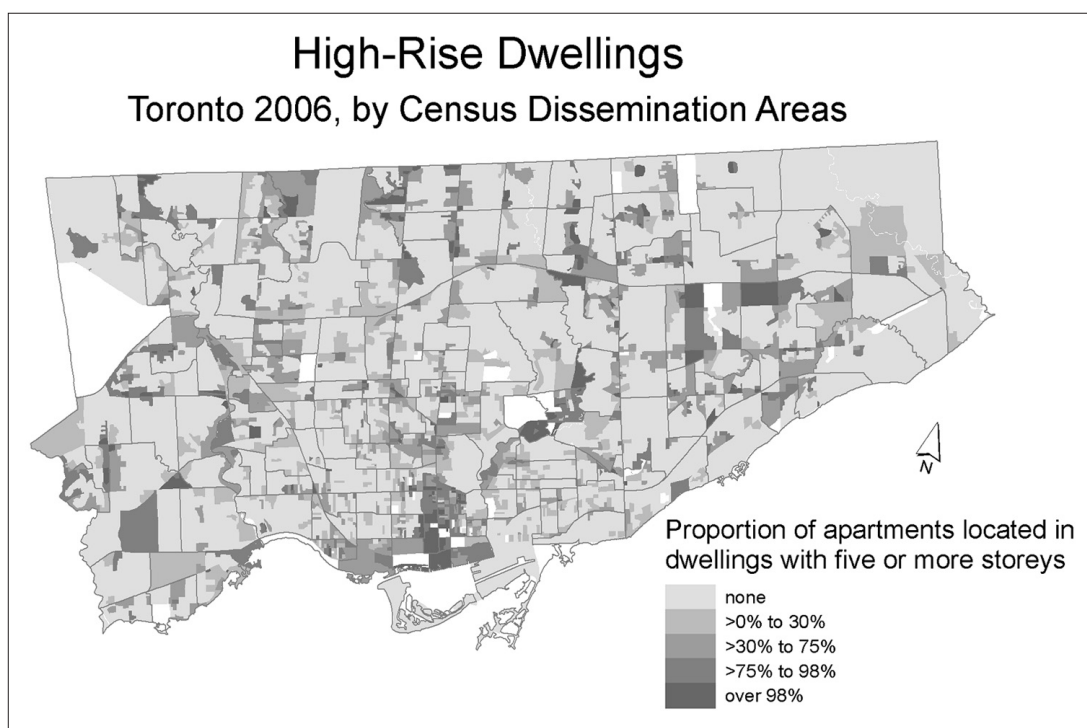

(a)

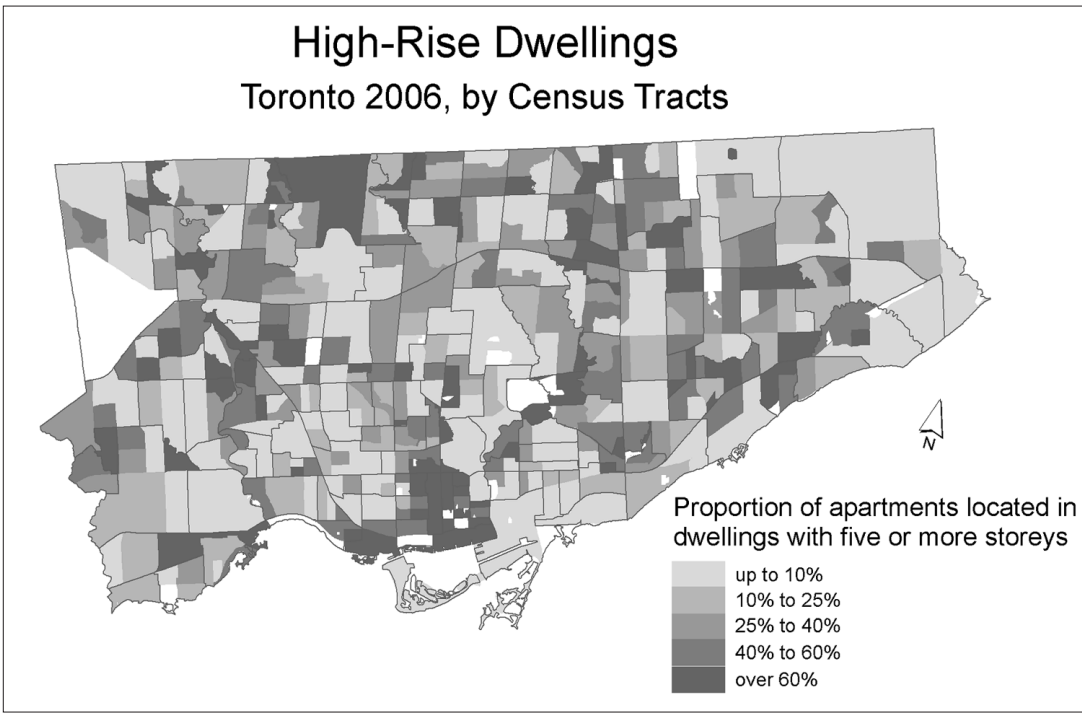

(b)

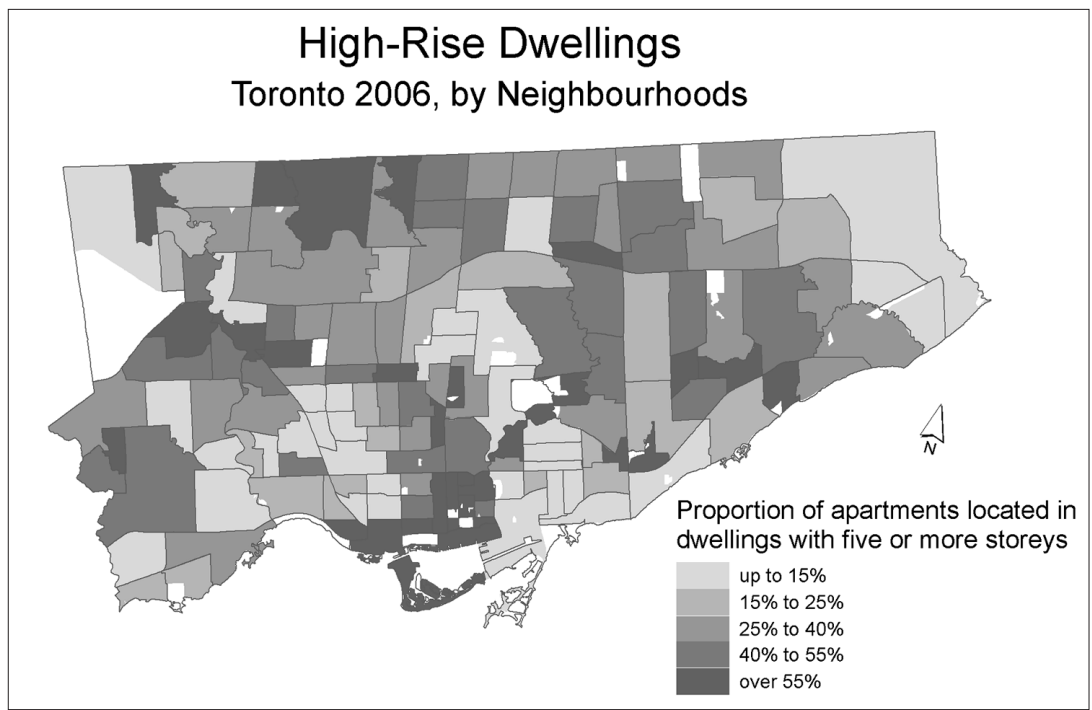

(c)

Figure 3. Dwelling units in high-rise buildings at different geographic scales: (a) 2001 census dissemination areas, (b) census tracts, and (c) City neighborhoods. (Data source: Statistics Canada.) 


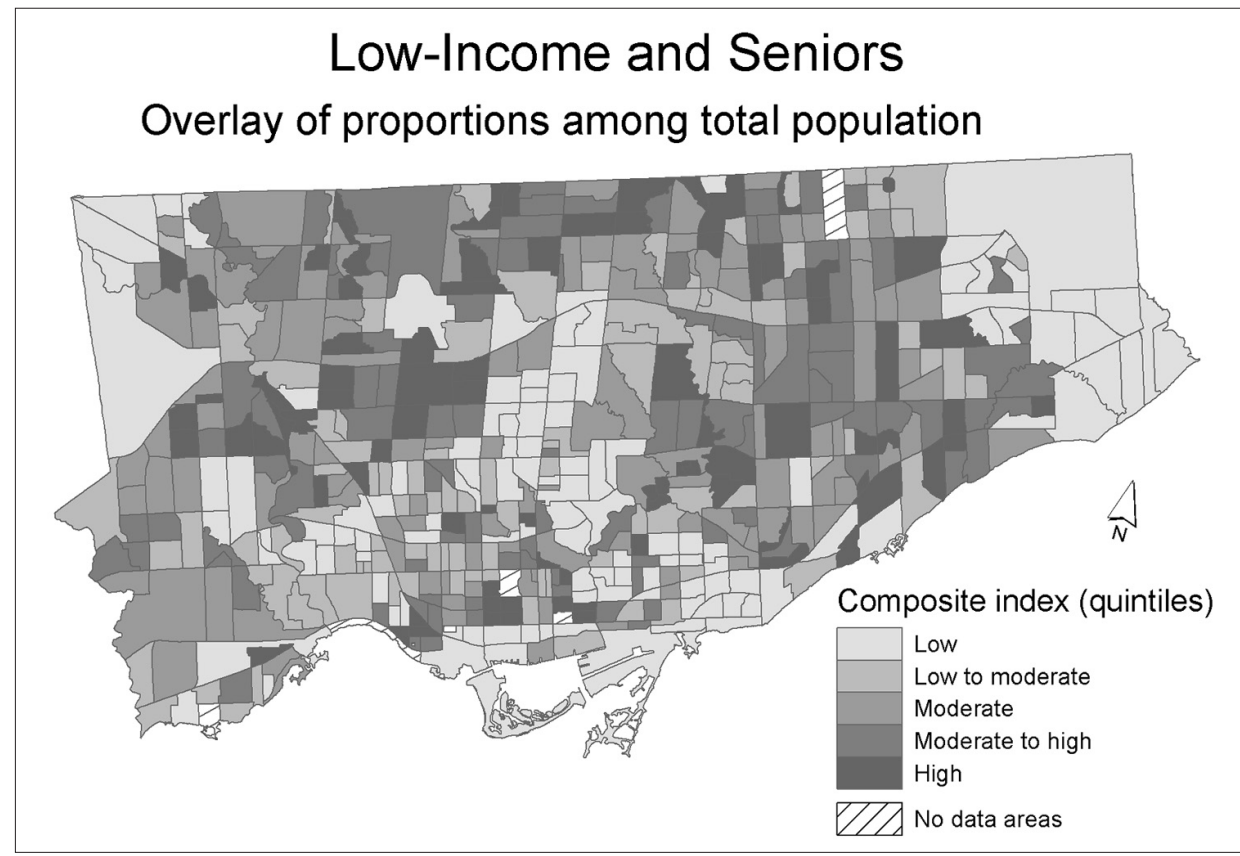

(a)

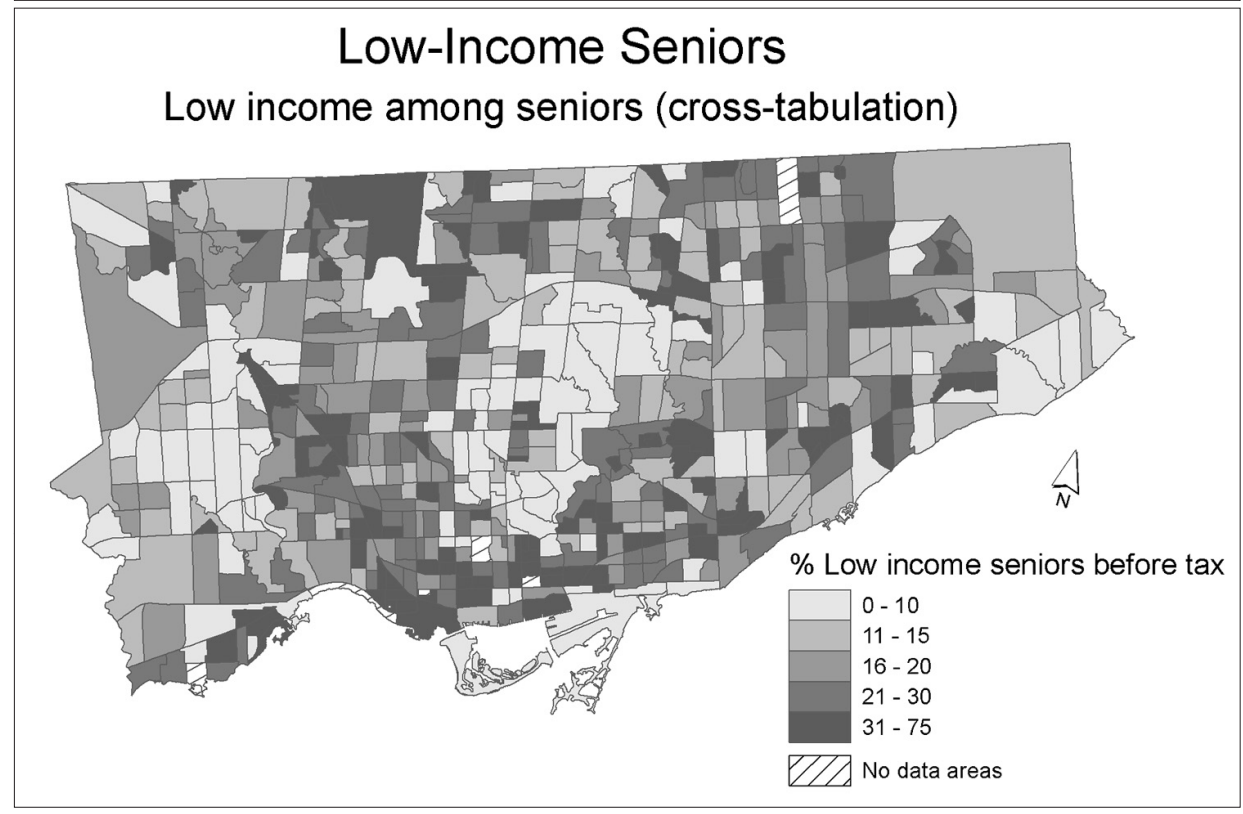

(b)

Figure 4. The impact of variable selection. (a) Overlay of low-income and seniors among total population vs. (b) low-income among seniors from cross-tabulated target profile. (Data source: Statistics Canada, Community Social Data Strategy.)

immigrants ( 5 percent), visible minority ( 5 percent), those without a degree ( 5 percent), persons aged 75 and older (15 percent), working age with disability (10 percent), and rates of ambulatory hospital visits for circulatory (7.5 percent) and respiratory (7.5 percent) disease. The index targeting seniors included those aged 65 and older among the total population (10 percent), aged 75 and older in private households ( 25 percent), low income seniors before tax (25 percent), seniors without a degree (10 percent), seniors without command of either official language (10 percent), seniors who are recent immigrants (10 percent), and visible minority seniors (10 percent). It should be noted that the composition of the indices is preliminary and limited by current data availability. The index maps are included here in order to illustrate the approach of using composite indices for the heat vulnerability assessment. 
An important requirement for effective spatial decision support is a concise summary of results. In order to simplify the intra-urban patterns of heat vulnerability, hot spots of vulnerability were identified for the general population index above using the LISA method. Figure 6 shows clusters of highly vulnerable CTs (hot spots) in dark grey and clusters of low vulnerability CTs (cool spots) in light grey. However, it is necessary to understand that these clustering patterns are highly dependent upon the input parameters for the LISA method. For example, a distinct degree of clustering results from statistical significance levels of 0.05 (Figure 6a) and 0.01 (Figure $6 \mathrm{~b}$ ). In addition, the LISA method in GeoDA employs a randomization approach producing slightly different clusters at each iteration, even when using identical significance levels.

\section{Consideration of \\ Decision-Makers' \\ Attitude towards Decision Risk}

The OWA method supports an explicit definition of decision strategies determined by the decision-maker's attitude towards risk. The risk-taking or optimistic strategy considers the highest scores for each decision alternative (e.g., for each CT), while the risk-averse or pessimistic strategy focuses on the lowest scores. For example, in the optimistic strategy, an area with a very high score in any of the criteria would perform well, irrespective of its other scores. Thus the decision-maker takes the risk of accepting a solution which has one very high score, but possibly several very low scores. In contrast, in the pessimistic strategy, a solution must have a satisfactory score, even in its weakest criterion, in order to perform well.

Figure 7 shows a series of screen shots of a quintile map which ranks CTs using a sample index of heat vulnerability, with the most vulnerable

\section{Potential Vulnerability to Heat \\ General population composite}

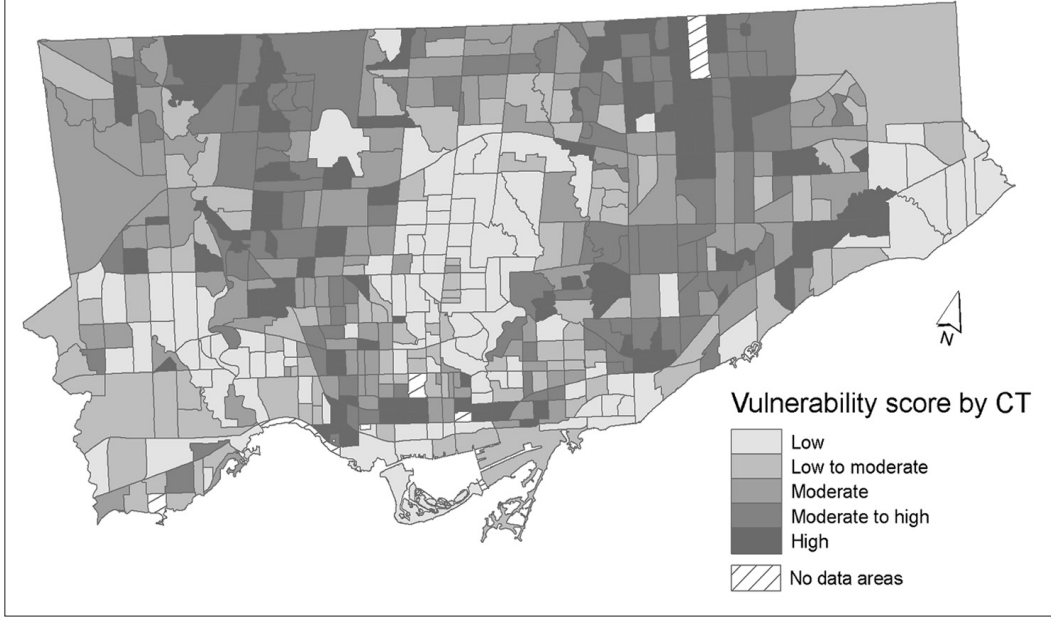

(a)

\section{Potential Vulnerability to Heat Seniors composite}

Figure 5. Addressing decision-maker needs. (a) Heat vulnerability index for the general population vs. (b) index for elderly population. (Data source: Statistics Canada, Ministry of Health and Long Term Care.)

CTs (lowest ranks) shown in dark color. When applying the optimistic strategy (Figure 7a), the most vulnerable CTs appear in a patchy pattern which follows the anecdotally known U-shape of population, with low socio-economic status in the City of Toronto extending from the northwest to the downtown area at the lake shore and harbor, and then towards the northeast (Rinner 2007). This fragmented pattern can be explained by the fact that it is sufficient for an area to have just one high score (low vulnerability indicator) in order to perform well (low overall vulnerability).

The neutral strategy (Figure 7b) is identical to a regular weighted average, i.e., it does not emphasize the high or low scores. Following this 


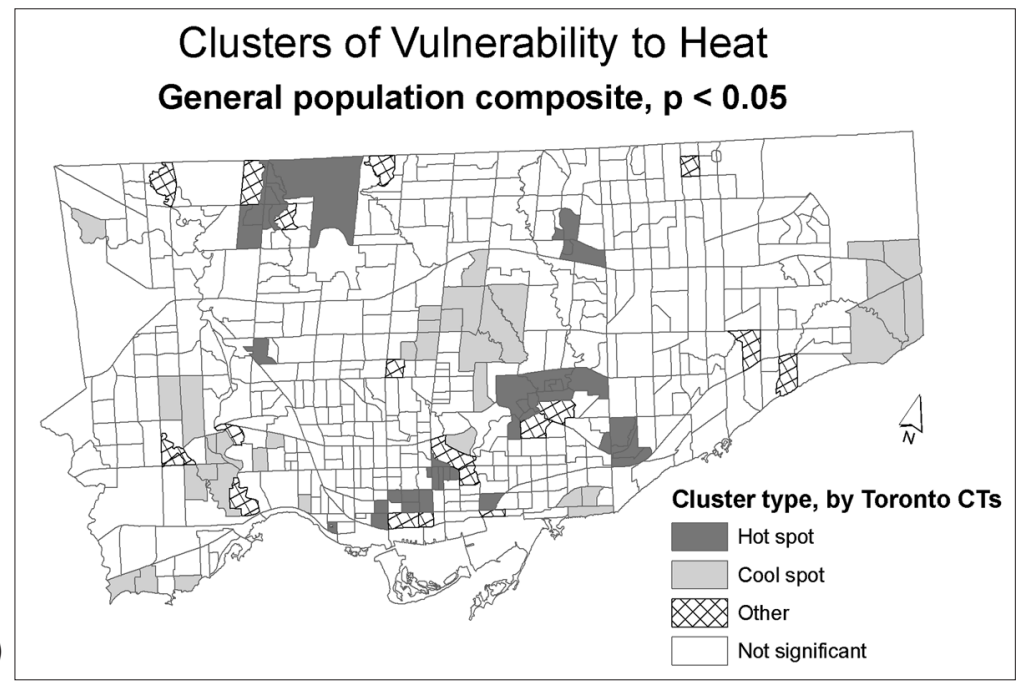

(a)

\section{Clusters of Vulnerability to Heat General population composite, $p<0.01$}

(b)

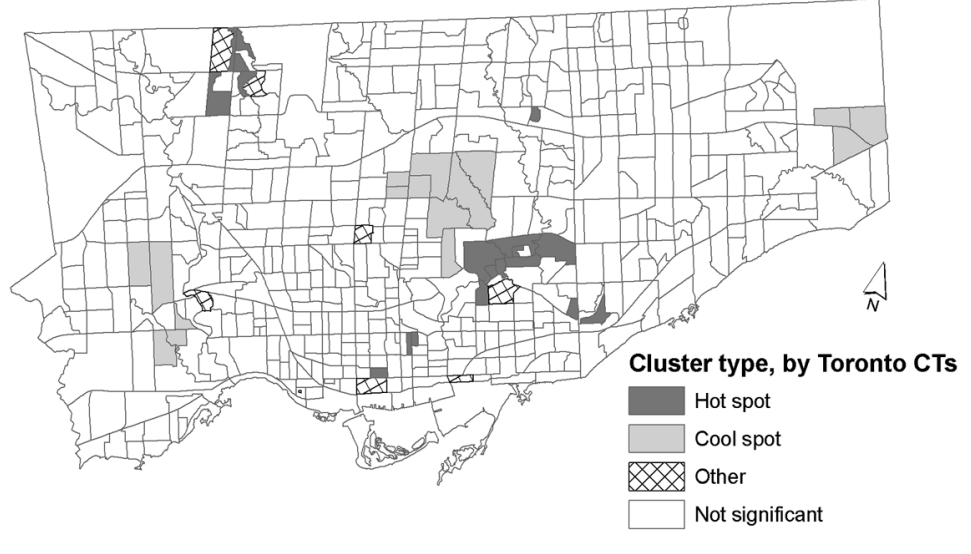

Figure 6. Hot spot maps for different parameters in LISA cluster analysis. (a) Significance level of 0.05 vs. (b) significance level of 0.01 . (Data source: Statistics Canada, Ministry of Health and Long Term Care.)

strategy produces the clearest representation of the previously mentioned U-shape, because low scores can be compensated by high scores, resulting in the fullest contribution of all criteria to the composite index for each area.

A different pattern appears in the pessimistic strategy (Figure 7c). The more vulnerable areas tend to move towards the outskirts of the City, and to cluster. The U-shape of deprived neighborhoods is more distinct in some areas, but it was interrupted in the downtown centre and the southeast ("The Beaches"). The City centre is now characterized by a large cluster of low vulnerability, which results from the fact that these areas have no low-scoring indicators at all. In contrast, some of the CTs in the northwest and northeast are newly developed and not shaded, and their high surface temperature values are sufficient to assess them as more vulnerable in the pessimistic, risk-averse decision strategy than in previous strategies.

\section{Conclusion and Outlook}

In this paper, we discussed the gaps in research addressing heat vulnerability at finer scale geography, such as the urban neighborhood level. We reported results from a preliminary assessment of population vulnerability to heat-related illness for the City of Toronto, Canada. Our assessment focused on the role of maps, and on cartographic design decisions, as elements of decision support and policy advice. The recommendations include creating multiple representations of vulnerability indicators, indices, and hot spots in order to avoid issues resulting from geographic aggregation and scale effects, variable selection, and the input parameters of cluster analysis and multi-criteria methods.

While it is anticipated that the preliminary project results will support hot weather planning and response in the current heat season, additional steps need to be taken to complete the vulnerability assessment. Additional exposure and sensitivity indicators as well as different composite vulnerability indices will be visualized, and overlays with adaptation measures such as available cool places created. The effectiveness of these maps and accompanying documentation needs to be assessed in interviews with Toronto Public Health staff and external stakeholders in community partner organizations. However, we envision that the maps can be used to help with preseason planning and operational heat response. For example, distribution of educational materials, information seminars, and first-aid training for hot weather could be targeted to organizations operating in neighborhoods where vulnerable people live. There is currently one community-level heat registry operating in Toronto; the vulnerability 
assessment may identify other areas which could benefit from such a program. The information will also help with decisions such as where to open cooling centers and extend swimming pool hours during extreme heat alerts.

Future research challenges can be grouped into three areas: the approach to combining individual risk factors into a composite vulnerability index; the use of more advanced spatial analysis techniques; and the validation of the vulnerability assessment. In our examples, indicators for exposure and sensitivity were combined in a composite measure of vulnerability. However, these two groups of indicators represent processes of a very different spatial, temporal, and substantial nature. For example, surface temperature is a continuous, ephemeral phenomenon, while urban form is much more stable over time and consists of well defined, discrete objects. Other ways to compare exposure and sensitivity without integrating them should be explored. Related research on testing the validity of the vulnerability assessment through heat-related mortality or morbidity cases also needs to be reviewed and a suitable method for Toronto devised.

\section{ACKNOWLEDGMENTS}

Staff at Toronto Public Health and the Clean Air Partnership provided assistance and feedback throughout this project. Dan Jakubek helped with data acquisition, while Blake Walker assisted with mapping and revised an earlier manuscript. The helpful comments by two anonymous reviewers and by the editor are also gratefully acknowledged. This research was partially funded by the Natural Sciences and Engineering Research Council of Canada (NSERC).

\section{REFERENCES}

Adger, W.N. 2006. Vulnerability. Global Environmental Change 16: 268-81.

Aniello, C., K. Morgan, A. Busbey, and L. Newland. 1995. Mapping micro-urban heat islands using Landsat ${ }^{\mathrm{TM}}$ and a GIS. Computers $\mathcal{E}$ Geosciences 21(8): 965-9.

Anselin, L. 1995. Local indicators of spatial association -LISA. Geographical Analysis 27: 93-115.

Barrow, M.W., and K.A. Clark. 1998. Heat-related illness. American Family Physician 58(3): 749-56.

Bassil, K.L., E. Gournis, E. Rea, F. Scott, and D. Cole. 2007. Utility of 911 ambulance dispatch data for

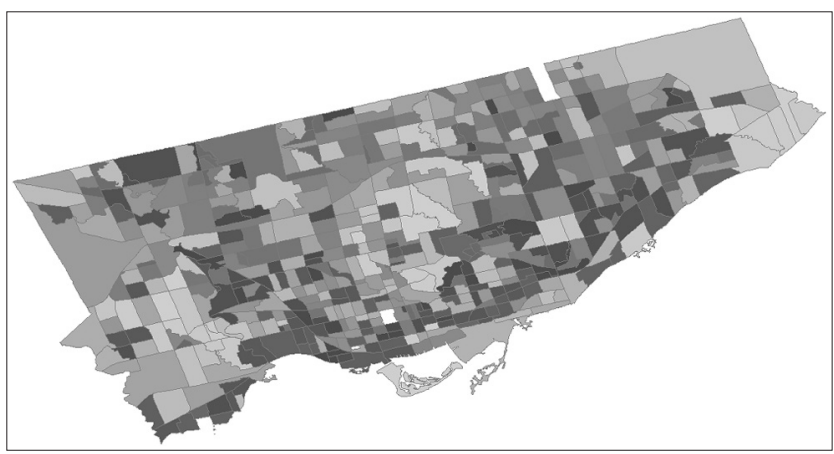

(a)

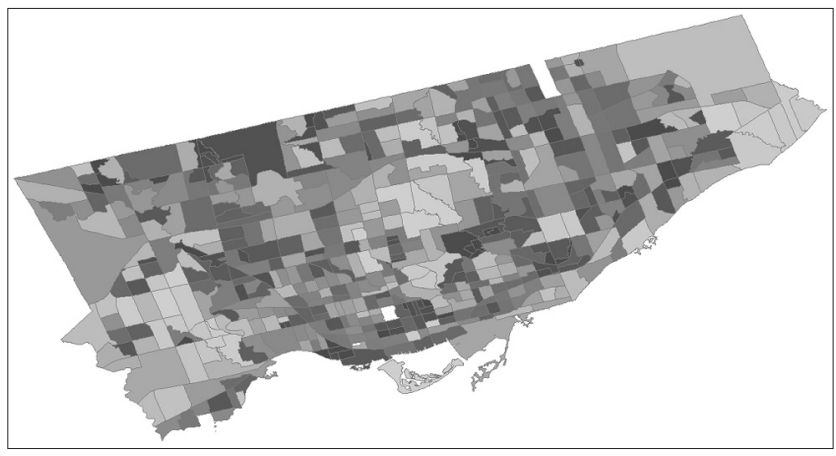

(b)

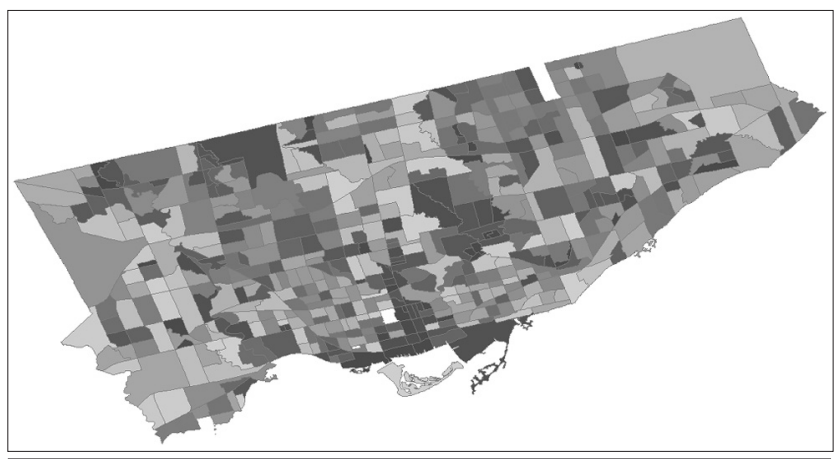

(c)

Figure 7. Screenshots of a heat vulnerability index across different OWA decision strategiesa; (a) optimistic, (b) neutral, and (c) pessimistic strategy. (Data source: Statistics Canada.)

the syndromic surveillance of heat-related illness in Toronto, Ontario, 2002-2005. Advances in Disease Surveillance 2: 143 [http://www.isdsjournal.org/ article/view/886].

Bassil, K.L. 2008. The relationship between temperature and 911 medical dispatch data for heat-related illness in Toronto, 2002-2005: An application of syndromic surveillance. PhD Thesis, Department of Public Health Sciences, University of Toronto.

Basu, R., and J.M. Samet. 2002. Relation between elevated ambient temperature and mortality: A review of the epidemiologic evidence. Epidemiologic Reviews 24(2): 190-202.

Bell, N., N. Schuurman, M. Hayes, and L. Oliver. 2007. Constructing place-specific measures of deprivation using local knowledge: Evaluating population health in Vancouver, British Columbia. The Canadian Geographer 51(4): 444-61. 
Bouchama, A., and J.P. Knochel. 2002. Heat stroke. The New England Journal of Medicine 346(25): 197888.

Brooks, N. 2003. Vulnerability, risk and adaptation: A conceptual framework. Tyndall Centre for Climate Change Research, Working Paper 38.

Cheng, C.S., M. Campbell, Q. Li, G. Li, H. Auld, N. Day, D. Pengelly, S. Gingrich, and D. Yap. 2007. A synoptic climatological approach to assess climatic impact on air quality in south-central Canada. Part I: Historical analysis. Water, Air, and Soil Pollution 182: $131-48$.

City of Toronto. 2009a. Neighbourhood profiles. [http:// www.toronto.ca/demographics/neighborhoods.htm].

City of Toronto. 2009b. Community social data strategy. [http://www.toronto.ca/demographics/csds.htm].

Cutter, S.L., J.T. Mitchell, and M.S. Scott. 2000. Revealing the vulnerability of people and places: A case study of Georgetown County, South Carolina. Annals of the Association of American Geographers. Association of American Geographers 90: 713-37.

Cutter, S.J., B.J. Boruff, and W.L. Shirley. 2003. Social vulnerability to environmental hazards. Social Science Quarterly 84(2): 242-61.

Cutter, S.L., and C. Finch. 2008. Temporal and spatial changes in social vulnerability to natural hazards. Proceedings of the National Academy of Sciences of the United States of America 105(7): 2301-6.

DiBiase, D. 1990. Visualization in the earth sciences. Pennsylvania State University, Bulletin of Earth and Mineral Sciences 59(2): 13-8.

Dolney, T.J., and S.C. Sheridan. 2006. The relationship between extreme heat and ambulance response calls for the City of Toronto, Ontario, Canada. Environmental Research 101: 94-103.

Eakin, H., and A.L. Luers. 2006. Assessing the vulnerability of social-environmental systems. Annual Review of Environment and Resources 31: 36594.

Ebi, K.L., J.B. Smith, I. Burton, and S. Hitz. 2005. Adaptation to climate variability and change from a public health perspective. In: K.L. Ebi, J.B. Smith, and I. Burton (eds), Integration of public health with adaptation to climate change. London, U.K.: Taylor and Francis. pp. 1-17.

Ebi, K.L. 2007. Towards an early warning system for heat events. Journal of Risk Research 10(5): 729-44.

Füssel, H.-M., R.J.T. Klein, and K.L. Ebi. 2004. Adaptation assessment for public health. In: B. Menne and K.L. Ebi (eds), European climate change health impact and adaptation assessment, Chapter 3. Cambridge, U.K.: Cambridge University Press.

Greenburg, J.H., J. Bromberg, C. Reed, T. Gustafson, and R. Beauchamp. 1983. The epidemiology of heat-related deaths, Texas - 1950, 1970-79, and 1980. American Journal of Public Health 73(7): 805-7.

Harlan, S.L., A.J. Brazel, L. Prashad, W.L. Stefanov, and L. Larsen. 2006. Neighborhood microclimates and vulnerability to heat stress. Social Science E Medicine 63: 2847-63.
Jankowski, P., N. Andrienko, and G. Andrienko. 2001. Map-centered exploratory approach to multiple criteria spatial decision making. International Journal of Geographical Information Science 15(2): 101-27.

Johnson, D.P., and J.S. Wilson. 2009. The socio-spatial dynamics of extreme urban heat events: The case of heat-related deaths in Philadelphia. Applied Geography (Sevenoaks, England) in press.

Kalkstein, L.S., and R.E. Davis. 1989. Weather and human mortality: An evaluation of demographic and interregional responses in the United States. Annals of the Association of American Geographers. Association of American Geographers 79(1): 44-64.

Kalkstein, L.S., and J.S. Greene. 1997. An evaluation of climate/mortality relationships in large US cities and possible impacts of climate change. Environmental Health Perspectives 105(1): 84-93.

Kilbourne, E.M. 1997. Heat waves and hot environments. In: E.K. Noji (ed), The public health consequences of disasters. Oxford University Press. pp. 245-69.

Loughnan, M. 2009. 'Hot Spots' project: Spatial vulnerability to heat events in Melbourne Australia. Conference abstract, Annual Meeting of the Association of American Geographers, March 22-27, 2009, Las Vegas, Nevada.

MacEachren, A.M. 1994. Visualization in modern cartography: Setting the agenda. In: A.M. MacEachren and D.R.F. Taylor (eds), Visualization in modern cartography. Oxford, U.K.: Pergamon. pp. 1-12.

MacEachren, A.M., C.A. Brewer, and L.W. Pickle. 1998. Visualizing georeferenced data: Representing reliability of health statistics. Environment E Planning A 30: 1547-61.

Malczewski, J., and C. Rinner. 2005. Exploring multicriteria decision strategies in GIS with linguistic quantifiers - A case study of residential quality evaluation. Journal of Geographical Systems 7(2): 249-68.

Maloley, M.J. 2009. Land surface temperature mapping of the greater Toronto area from Landsat TM/ETM + thermal imagery: 1987-2008. Report, Canada Centre for Remote Sensing, Natural Resources Canada.

McGeehin, M.A., and M. Mirabelli. 2001. The potential impacts of climate variability and dhange on temperature-related morbidity and mortality in the United States. Environmental Health Perspectives 109: 185-9.

McGregor, G., and T. Wolf. 2008. Development and validation of an index for mapping heat vulnerability hotspots in urban areas. Presentation at the 18th International Congress of Biometeorology, 22-26 September 2008, Tokyo, Japan.

McKendry, J.E., and G.E. Machlis. 2008. Cartographic design and the quality of climate change maps. Climatic Change, published online.

Mersereau, V. 2007. A scan of municipal heat/health watch warning systems and hot weather response plans. Toronto, Ontario: Clean Air Partnership. 
Monmonier, M. 1989. Geographic brushing: Enhancing exploratory analysis of the scatterplot matrix. Geographical Analysis 21: 81-4.

NWS. 2008. Natural Hazard Statistics. Silver Spring, MD: National Oceanic and Atmospheric Administration, National Weather Service, Office of Climate, Water, and Weather Services. [http://www. nws.noaa.gov/om/hazstats.shtml].

Openshaw, S. 1984. The modifiable areal unit problem. Concepts and techniques in modern geography. Norwich, U.K.: Geobooks. Vol. 38.

Pengelly, L.D., M.E. Campbell, C.S. Cheng, C. Fu, S.E. Gingrich, and R. Macfarlane. 2007. Anatomy of heat waves and mortality in Toronto: Lessons for public health protection. Canadian Journal of Public Health 98(5): 364-8.

Rinner, C., and J. Malczewski. 2002. Web-enabled spatial decision analysis using ordered weighted averaging (OWA). Journal of Geographical Systems 4(4): 385-403.

Rinner, C., and J.P. Taranu. 2006. Map-based exploratory evaluation of non-medical determinants of population health. Transactions in GIS 10(4): 633-49.

Rinner, C. 2007. A geographic visualization approach to multi-criteria evaluation of urban quality of life. International Journal of Geographical Information Science 21(8): 907-19.

Schroeter, D., et al. 2004. The ATEAM final report 2004 - Detailed report related to overall project duration. Advanced Terrestrial Ecosystem Analysis and Modelling, pp. 139. Potsdam Institute for Climate Impact Research (PIK), Potsdam, Germany. [http://www.pik-potsdam.de/ateam/ateam_final_ report sections 5 to 6.pdf].

Schuurman, N., N. Bell, J. Dunn, and L. Oliver. 2007. Deprivation indices, population health and geography: An evaluation of the spatial effectiveness of indices at multiple scales. Journal of Urban Health 84(4): 591-603.

Séguin, J., and K.-L. Clarke. 2008. Introduction. In: J. Seguin (ed), Human health in a changing climate: A Canadian assessment of vulnerabilities and adaptive capacity. Ottawa, Canada: Health Canada.

Semenza, J.C., J.E. McCullough, W.D. Flanders, M.A. McGeehin, and J.R. Lumpkin. 1999. Excess hospital admissions during the July 1995 heat wave in Chicago. American Journal of Preventive Medicine 16(4): 269-77.

Slocum, T.A., R.B. McMaster, F.C. Kessler, and H.H. Howard. 2009. Thematic cartography and geovisualization, 3rd ed. Upper Saddle River, New Jersey: Prentice Hall.

Smoyer-Tomic, K.E., and D. Rainham. 2001. Beating the heat: Development and evaluation of a Canadian hot weather health-response plan. Environmental Health Perspectives 109: 1241-8.

Smoyer-Tomic, K.E., R. Kuhn, and A. Hudson. 2003. Heat wave hazards: An overview of heat wave impacts in Canada. Natural Hazards 28: 463-85.
Statistics Canada. 2009. Census tract profiles. [http:// www12.statcan.gc.ca/census-recensement/2006/dp$\mathrm{pd} /$ prof/92-597/index.cfm?Lang $=\mathrm{E}]$.

Swift, A., L. Liua, and J. Uber. 2008. Reducing MAUP bias of correlation statistics between water quality and GI illness. Computers, Environment and Urban Systems 32(2): 134-48.

Tan, J.G. 2008. Commentary: People's vulnerability to heat wave. International Journal of Epidemiology 37(2): 318-20.

Tomlinson, R. 2007. Thinking about GIS, 3rd ed. Redlands, California: ESRI Press.

Toronto Public Health. 2007. Hot weather response plan update. Staff Report, Medical Officer of Health, November 20, 2007.

Toronto Public Health. 2009a. Heat alerts and extreme heat alerts. [http://www.toronto.ca/health/heatalerts/ index.htm].

Toronto Public Health. 2009b. City of Toronto--Hot weather response plan 2009. [http://www.toronto.ca/ health/heatalerts/pdf/hwr plan 2009.pdf].

U.S. EPA. 2006. Excessive heat events guidebook. Washington, D.C.: Office of Atmospheric Programs, United States Environmental Protection Agency. [http://www.epa. gov/hiri/about/pdf/EHEguide final.pdf].

Vincent, K. 2004. Creating an index of social vulnerability to climate change for Africa. Working Paper 56, Tyndall Centre for Climate Change Research, University of East Anglia, Norwich, U.K.

Walker, A.. 2006. Vulnerability: Who's most at risk? In Health Canada: Climate change: Preparing for the health impacts. Health Policy Research Bulletin: Issue 11, Chapter 6. [http://www.hc-sc.gc.ca/sr-sr/ pubs/hpr-rpms/bull/2005-climat/index-eng.php].

Wilhelmi, O. 2007. Annual report, SocietalEnvironmental Research and Education (SERE) Laboratory, National Center for Atmospheric Research (NCAR). [http://www.sere.ucar.edu/ LAR/2007/catalog/wilhelmi.html].

Wilhelmi, O., C. Uejio, J. Golden, D. Mills, and J. Samenow. 2008. Intra-urban spatial patterns of societal risk and vulnerability to extreme heat. Geophysical Research Abstracts 10: EGU2008-A-05813 [http://www.cosis.net/abstracts/EGU2008/05813/ EGU2008-A-05813.pdf].

Yager, R. 1988. On ordered weighted averaging aggregation operators in multi-criteria decision making. IEEE Transactions on Systems, Man, and Cybernetics 18: 183-90.

Yohe, G., and K.L. Ebi. 2005. Approaching adaptation: Parallels and contrasts between the climate and health communities. In: K.L. Ebi, J. Smith, and I. Burton (eds), Integration of public health with adaptation to climate change: Lessons learned and new directions. London, UK: Taylor and Francis. pp. 18-43. 